\title{
Trends in HbA1c and Body Mass Index Among Individuals with Type 2 Diabetes: Evidence from a US Database 2012-2019
}

Kristina S. Boye $\cdot$ Maureen J. Lage (1) - Shraddha Shinde •

Vivian Thieu $\cdot$ Jay Patrick Bae

Received: February 24, 2021 / Accepted: May 18, 2021 / Published online: June 2, 2021

(C) The Author(s) 2021

\section{ABSTRACT}

Introduction: Given the high rates of obesity and poor glycemic control among individuals with type 2 diabetes (T2D), this study examines current trends in HbA1c and body mass index (BMI) as well as the association between HbA1c and BMI among adults with T2D.

Methods: Data from the IBM ${ }^{\circledR}$ MarketScan ${ }^{\circledR}$ Explorys ${ }^{\circledR}$ Claims-EMR Data were used to construct eight annual cohorts for the years 2012-2019. Each annual cohort included adults identified with T2D who had at least one recorded $\mathrm{HbA1c}$ laboratory result and BMI value in the year of interest. Given these cohorts, trends in $\mathrm{HbA} 1 \mathrm{c}$ and BMI were described over time using generalized estimating equation (GEE) tests.

Results: Results indicate that, over the study period from 2012-2019, average BMI increased significantly and there was a decrease in the percentage of adults with T2D who achieved glycemic control. In addition, for all years, higher BMI classification was associated with higher HbA1c values. When examining results for patients in different age groups, the findings were generally consistent with the overall population. In each age group, but most notably the age 18-44 group, the mean BMI increased over time and higher BMI was associated with higher HbA1c.

Conclusion: Given the increase in BMI and decreasing percentage of individuals achieving glycemic control among adults with T2D found over the study period, therapies which decrease BMI as well as HbA1c can potentially have a significant impact on the management of T2D. The growing proportion of the younger age group with higher mean BMI may remain a key subgroup of interest.

Keywords: Body mass index; HbA1c; Trends; Type 2 diabetes

K. S. Boye $\cdot$ S. Shinde $\cdot$ V. Thieu $\cdot$ J. P. Bae Eli Lilly and Company, Lilly Corporate Center, Indianapolis, IN 46285, USA

M. J. Lage $(\bowtie)$

HealthMetrics Outcomes Research, 27576 River

Reach Drive, Bonita Springs, FL 34134, USA

e-mail: lagemj@hlthmetrics.com 


\section{Key Summary Points}

Why carry out this study?

In the US, the rate of obesity has increased among adults with diabetes, with implications for both treatments and health outcomes.

This study updates trends in body mass index (BMI) and HbA1c in a US population with type 2 diabetes (T2D) and examines the relationship between BMI and $\mathrm{HbA} 1 \mathrm{c}$.

\section{What was learned from the study?}

Among individuals with T2D, from 2012 to 2019 mean BMI increased and the percentage of individuals who achieved glycemic control decreased.

For all adults with T2D, higher BMI was generally associated with higher $\mathrm{HbA1c}$ levels.

The results of this study suggest that therapies which decrease BMI as well as HbA1c may be important in the management of T2D.

\section{DIGITAL FEATURES}

This article is published with digital features, including a summary slide, to facilitate understanding of the article. To view digital features for this article go to https://doi.org/10.6084/ m9.figshare.14610426.

\section{INTRODUCTION}

Multiple studies drawing from a variety of data sources have shown that the rate of obesity has increased in the USA over the past 40 years [1]. Among American adults with diagnosed diabetes, the frequency of overweight and obesity has likewise risen, from an estimated $78.5 \%$ in
1988-1994 to $85.2 \%$ in 1999-2002 [2] and $89.0 \%$ in 2013-2016 [3]. These trends may have implications for diabetes treatment. Previous research among individuals with type 2 diabetes (T2D) has indicated that overweight and obesity increase the risk of cardiovascular and other diseases and make it harder to sustain glycemic control [4]. In addition, a synthesis of data from 51 randomized control trials and 7 prospective single-arm studies revealed a consistent, linear relationship between weight loss and decreased HbA1c among people with T2D who were overweight or obese [5]. The American Diabetes Association (ADA) has stated that " $[\mathrm{t}]$ here is strong and consistent evidence that obesity management...is beneficial in the treatment of type 2 diabetes" [6].

Given that much of the research cited above relied upon data now a decade old or older $[4,5,7]$, one purpose of the present study was to provide updated statistics on trends in body mass index (BMI) and HbA1c in a US population with T2D. The second main purpose was to reexamine the relationship between BMI and HbA1c. Given these aims, the present analyses used claims data collected in naturalistic treatment settings to explore trends in BMI and HbA1c and the association between the two measures.

\section{METHODS}

The analyses were conducted with the IBM ${ }^{\circledR}$ MarketScan ${ }^{\circledR}$ Explorys ${ }^{\circledR}$ Claims-EMR database, which links administrative claims, laboratory results, and clinical observations to supply information on individual characteristics, diagnoses, procedures, outpatient prescription drug use, HbA1c laboratory test results, and records of height, weight, and BMI. The claims data contain information on fully paid and adjudicated claims and capture information for over 263 million individuals since 1995 on physician office visits, hospital stays, retail, mail order and specialty pharmacies, and carve-out care such as mental health services, while the laboratory data contain laboratory test results [8]. The MarketScan ${ }^{\circledR}$ data used in this study are based upon a large convenience sample and were 
mostly obtained from large employers [8]. The EMR data provided for this study were built upon clinical data and capture information for more than 63 million unique patients. The EMR data include data from ambulatory services, specialty care, and inpatient care [9]. All data for this study were fully de-identified and Health Insurance Portability and Accountability Act (HIPAA) compliant and represented medical encounters that took place between January 1, 2012, and December 31, 2019. Use of the data was obtained by Eli Lilly and Company via the purchase of a data license from International Business Machines (IBM) Corp. In addition, a data access rider from IBM allowed HealthMetrics Outcomes Research to access the data. Given the use of retrospective and de-identified data, ethics committee approval was not required.

A prevalence cohort was constructed for each year from 2012 through 2019. Given this 8-year time span, there were eight annual cohorts. Individuals were included in an annual cohort if, in the year of interest, they had: (1) two or more diagnoses of $\mathrm{T} 2 \mathrm{D}$, (2) a recorded age of 18 years or older, (3) at least one recorded HbA1c, and (4) at least one recorded BMI. Individuals were excluded from the annual cohort if they had a diagnosis of gestational diabetes or pregnancy or a discontinuation of insurance in the calendar year of interest.

Given the eight annual cohorts, the analyses examined trends in $\mathrm{HbA} 1 \mathrm{c}$, trends in BMI, and the relationship between BMI and $\mathrm{HbA1c}$, based upon the last recorded BMI or HbA1c value for each year of interest. Trends in HbA1c focused on the American Diabetes Association (ADA) target of $\mathrm{HbA1c}<7 \%$ for most adults [10], while trends in BMI focused on the Centers for Disease Control and Prevention (CDC) BMI categories [11]. Trends in HbA1c and BMI were described over time with no adjustments for confounding using generalized estimating equation (GEE) tests [12]. In addition, trends were examined for age groups, as categorized by the CDC in their National Diabetes Statistics Report [3]. Means and standard deviations were reported for continuous variables, and percentages were reported for categorical variables. All analyses were conducted using SAS version 9.4, and a $P$ value $<0.05$ was considered, a priori, to be statistically significant.

\section{RESULTS}

Table 1 shows sample size and characteristics of the individuals with T2D over the years 2012-2019. Table 1 shows that, over the study duration, the average age decreased and, in general, there were slightly more males than females. Figure 1 illustrates that the mean BMI increased over the study period, from $33.2 \mathrm{~kg} /$ $\mathrm{m}^{2}$ in 2012 to $34.5 \mathrm{~kg} / \mathrm{m}^{2}$ in 2019 . Accordingly, there was a decrease in the percentage of adults who were classified as normal weight or overweight and an increase in the percentage of adults identified as obese class I, obese class II, or obese class III, with all trends statistically significant. Both the decreasing trend in the percentage of normal weight individuals and the increasing trend in the percentage of individuals identified as obese class III were statistically significant. Overall, there was no statistically significant trend in HbA1c over the study period.

Table 2 examines the relationship between BMI and HbA1c. Results indicate that over the time period from 2012 to 2019 for all individuals and for all benchmark BMI classifications (normal weight, overweight, obese class I, obese class II, and obese class III), there was a decrease in the percentage of individuals with $\mathrm{HbA} 1 \mathrm{c}$ at the ADA recommended target of $<7 \%$ [10] and an increase in the percentage of people with HbA1c $\geq 7 \%$. For all weight classifications except obese class III, the decreasing trend in the percentage of individuals with HbA1c $<7 \%$ and the increasing trend in the percentage of individuals with $\mathrm{HbA} 1 \mathrm{c} \geq 7 \%$ were statistically significant. In addition, Table 2 reveals that, in general, higher benchmark BMI was associated with worse glycemic control, as indicated by a higher proportion of patients having post-period $\mathrm{HbA} 1 \mathrm{c} \geq 7 \%$.

Figure 2 illustrates changes in mean $\mathrm{HbA1c}$ stratified by BMI classification. Most compellingly, Fig. 2 descriptively illustrates that, without exception and for each year of study, higher BMI categorization was associated with 


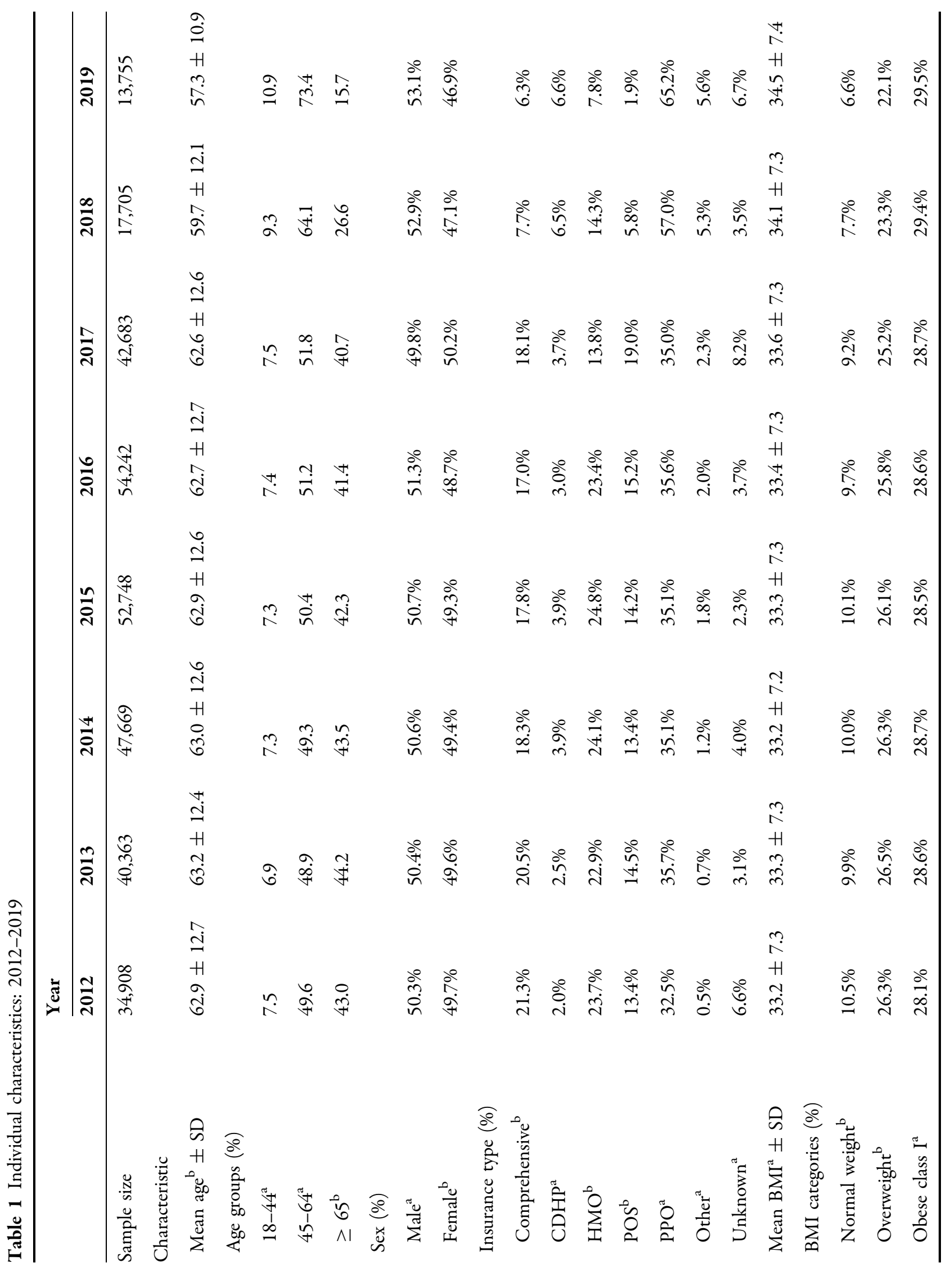




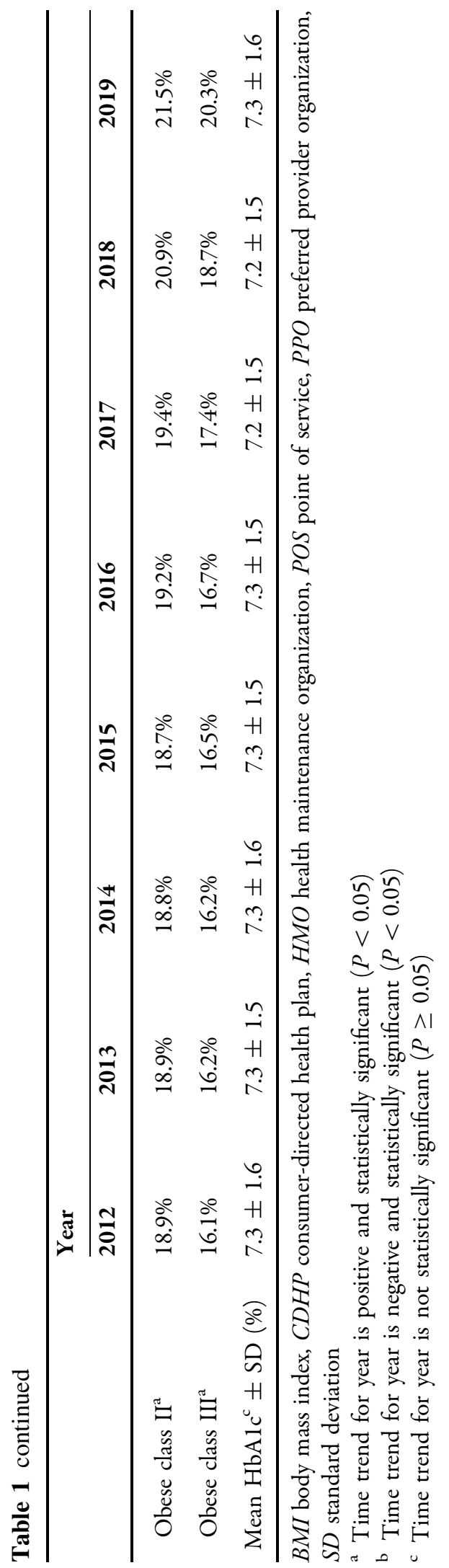

higher mean HbA1c. These results are consistent with Table 2, which found higher BMI classification was associated with worse glycemic control. In addition, Fig. 2 shows that the obese class III category was associated with a statistically significant downward trend in mean HbA1c. Regardless of these trends, however, Fig. 2 reveals that the obese class III cohort had the highest mean HbA1c for every year of study.

Figure 3 illustrates trends in BMI and $\mathrm{HbA1c}$ stratified by age groups. Results reveal that individuals aged 18-44 years had the highest mean BMI and $\mathrm{HbA1c}$, while individuals aged 65 or older had the lowest mean BMI and HbA1c. For all age groups, but most notably for those individuals aged 18-44, mean BMI showed a statistically significant increase in trend over the time period from 2012 to 2019, while mean HbA1c declined significantly for individuals aged $18-44$ or $45-64$ years over the study period.

Given the reduction in sample size which occurred in our dataset post 2017, all trend tests were conducted a second time, focusing exclusively on the years 2012-2017 (i.e., removing the years 2018 and 2019). These alternative trend test results were generally consistent with the statistics reported above. Specifically, decreases in mean age and increases in both mean HbA1c and mean BMI were statistically significant over the time period 2012-2017. However, in contrast to the primary analyses, the sensitivity analyses found no change in the percentage of all individuals or normal weight individuals with $\mathrm{HbA} 1 \mathrm{c} \geq 7 \%$ over the time period from 2012 to 2017 . In addition, the alternative analyses found a significant decline over time in the percentage of obese class III individuals with $\mathrm{Hba1c} \geq 7 \%$.

\section{DISCUSSION}

In this retrospective, descriptive study, individuals with higher weight classifications also had higher HbA1c. In addition, mean BMI increased while the percentage of patients identified as having glycemic control decreased. These results are consistent with previous research 

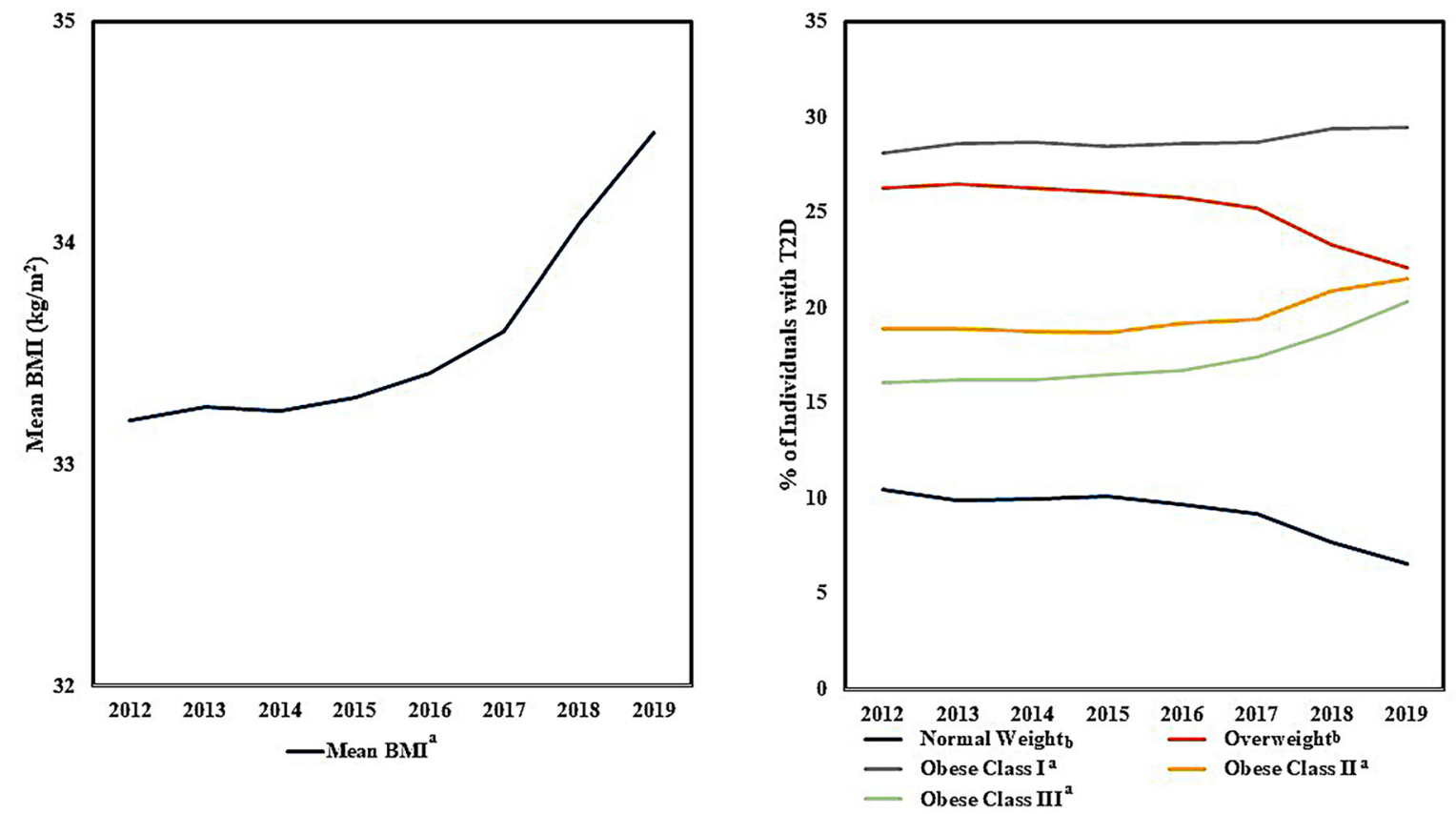

$\mathrm{a}$ - trend is positive and statistically significant $(\mathrm{P}<0.05) ; \mathrm{b}$-trend is negative and statistically significant $(\mathrm{P}<0.05)$; $\mathrm{c}-$ trend is not statistically significant $(\mathrm{P} \geq 0.05)$ BMI - body mass index

Fig. 1 Trends in body mass index: 2012-2019

which has shown higher BMI and higher HbA1c to be positively correlated $[13,14]$.

The increase in BMI observed over the study period, with $89.5 \%$ classified as overweight or obese in 2012 and $93.4 \%$ in 2019, continues an upward BMI trend observed in an earlier study of a population of US adults with diabetes, in which the proportion with obesity rose from $33 \%$ in $1970-1974$ to $49 \%$ in $1985-1989$ [15]. The increase in mean HbA1c observed in this study is consistent with research which has found a linear increase in HbA1c levels with increasing BMI [16] as well as with a literature review which examined real-world studies of BMI and HbA1c in eight countries [17]. Notably, the increase in mean $\mathrm{HbA} 1 \mathrm{c}$, from $7.25 \%$ in 2012 to $7.32 \%$ in 2019 , occurred despite changes in diabetes therapy since 2012, including a growth in the use of GLP-1 RAs and the introduction of SGLT-2s and insulin-GLP combinations products [18-20].

Consistent with the rise in mean HbA1c for all individuals and for those of normal weight, overweight, obese class I, or obese class II, the proportion who were unable to achieve the
ADA treatment target of HbA1c $<7 \%$ [10] grew over the 8-year time frame. This finding contrasts with research from an earlier time horizon, which found that the percentage of people with diabetes who attained the HbA1c goal of $<7 \%$ rose from $50.9 \%$ in 1988-1994 to $58.8 \%$ in $2005-2010$ [7]. However, the present findings are in concert with a retrospective analysis based on claims data from a more recent time period (2009-2011), which concluded that being overweight or obese was consistent with suboptimal glycemic control [13]. Furthermore, a literature review of realworld studies reporting data on HbA1c and BMI concluded that "Overall, studies have shown that the proportion of patients failing to achieve glycemic control increases with overweight or obesity" [17].

Results for individuals based on age groups were also generally consistent with prior research. For example, consistent with the literature review discussed above [17], the group with the highest mean HbA1c (age 18-44) also had had the highest mean BMI, while patients with the lowest mean HbA1c (age 65 years or 
Table 2 Distribution of HbA1c by BMI categories from 2012-2019

\begin{tabular}{|c|c|c|c|c|c|c|c|c|}
\hline \multirow[t]{2}{*}{ Distribution of HbA1c by BMI categories } & \multicolumn{8}{|l|}{ Year } \\
\hline & 2012 & 2013 & 2014 & 2015 & 2016 & 2017 & 2018 & 2019 \\
\hline \multicolumn{9}{|l|}{$\%$ of all T2D individuals } \\
\hline$<7 \%^{\mathrm{b}}$ & 53.4 & 53.3 & 52.7 & 53.0 & 52.3 & 54.4 & 52.4 & 51.1 \\
\hline$\geq 7 \%^{\mathrm{a}}$ & 46.6 & 46.7 & 47.3 & 47.0 & 47.7 & 45.6 & 47.6 & 48.9 \\
\hline \multicolumn{9}{|l|}{$\%$ of normal weight $\mathrm{T} 2 \mathrm{D}$ individuals } \\
\hline$<7 \%^{\mathrm{b}}$ & 61.6 & 62.1 & 61.2 & 60.8 & 61.1 & 62.0 & 60.4 & 57.0 \\
\hline$\geq 7 \%^{\mathrm{a}}$ & 38.4 & 37.9 & 38.8 & 39.2 & 38.9 & 38.0 & 39.6 & 43.0 \\
\hline \multicolumn{9}{|l|}{$\%$ of overweight $\mathrm{T} 2 \mathrm{D}$ individuals } \\
\hline$<7 \%^{\mathrm{b}}$ & 58.6 & 57.8 & 56.6 & 56.1 & 55.9 & 57.4 & 54.9 & 55.5 \\
\hline$\geq 7 \%^{\mathrm{a}}$ & 41.4 & 42.2 & 43.4 & 43.9 & 44.1 & 42.6 & 45.1 & 44.5 \\
\hline \multicolumn{9}{|l|}{$\%$ of obese class I T2D individuals } \\
\hline$<7 \%^{\mathrm{b}}$ & 52.4 & 52.4 & 51.7 & 51.9 & 52.4 & 53.7 & 52.1 & 50.6 \\
\hline$\geq 7 \%^{\mathrm{a}}$ & 47.6 & 47.6 & 48.3 & 48.1 & 48.7 & 46.3 & 47.9 & 49.4 \\
\hline \multicolumn{9}{|l|}{$\%$ of obese class II T2D individuals } \\
\hline$<7 \%^{\mathrm{b}}$ & 49.3 & 49.8 & 48.5 & 49.7 & 48.9 & 51.6 & 49.9 & 49.1 \\
\hline$\geq 7 \%^{\mathrm{a}}$ & 50.7 & 50.2 & 51.5 & 50.3 & 51.1 & 48.4 & 50.1 & 50.9 \\
\hline \multicolumn{9}{|l|}{$\%$ of obese class III T2D individuals } \\
\hline$<7 \%^{\mathrm{c}}$ & 45.9 & 46.1 & 47.6 & 48.9 & 47.5 & 50.5 & 49.3 & 47.3 \\
\hline$\geq 7 \%^{\mathrm{c}}$ & 54.1 & 53.9 & 52.4 & 51.1 & 52.5 & 49.5 & 50.7 & 52.7 \\
\hline
\end{tabular}

$B M I$ body mass index, $T 2 D$ type 2 diabetes

a Time trend for year is positive and statistically significant $(P<0.05)$

b Time trend for year is negative and statistically significant $(P<0.05)$

c Time trend for year is not statistically significant $(P \geq 0.05)$

older) also had the lowest mean BMI. In addition, the finding that age is inversely related to mean $\mathrm{HbA1c}$ is consistent with research from the CDC which found that individuals with diabetes aged 18-44 years had the highest percentage of individuals with $\mathrm{HbA} 1 \mathrm{c} \geq 8 \%$ or $10 \%$, while individuals with diabetes aged 65 or older had the lowest percentage of individuals with $\mathrm{HbA1c} \geq 8 \%$ [3]. Prior research has also found that weight gain in early adulthood is associated with a higher risk of onset of T2D compared to weight gain later in life [21]. Such a finding is consistent with results of this study that found higher BMI among younger adults with T2D.

The strengths of the present analyses include a large source database and an extended time horizon. Nevertheless, the results should be interpreted within the context of the limitations. Most notably, the use of data from a convenience sample that captures information predominantly from large employers means that results may not be generalizable to the entire US population. Moreover, the sample size was affected by the requirement of recorded $\mathrm{BMI}$ and HbA1c results, and only one BMI and 


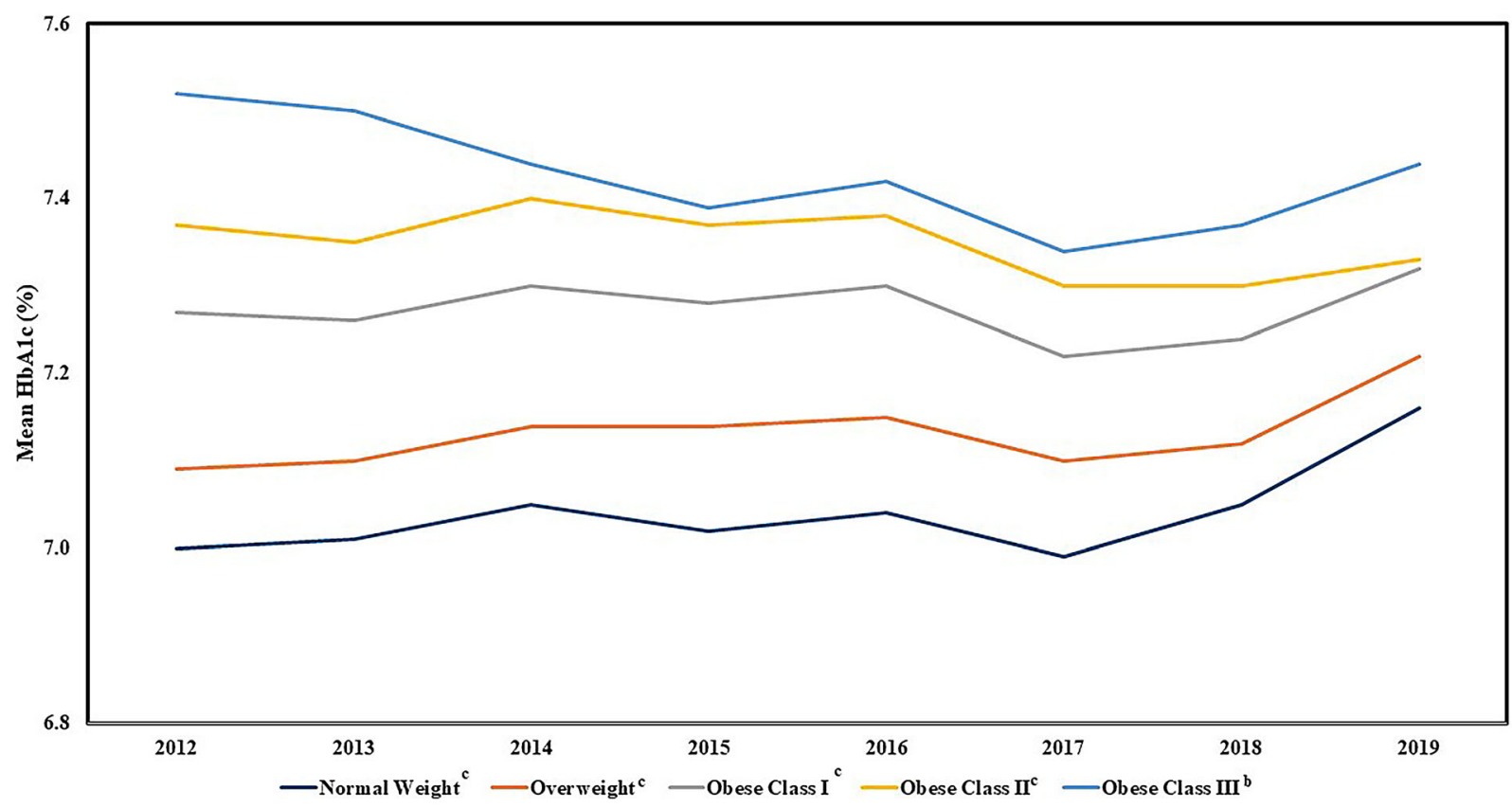

a - trend is positive and statistically significant $(P<0.05) ; b-$ trend is negative and statistically significant $(\mathrm{P}<0.05)$; $c-$ trend is not statistically significant $(P \geq 0.05)$

Fig. 2 Trends in HbAlc from 2012-2019: by body mass index categories
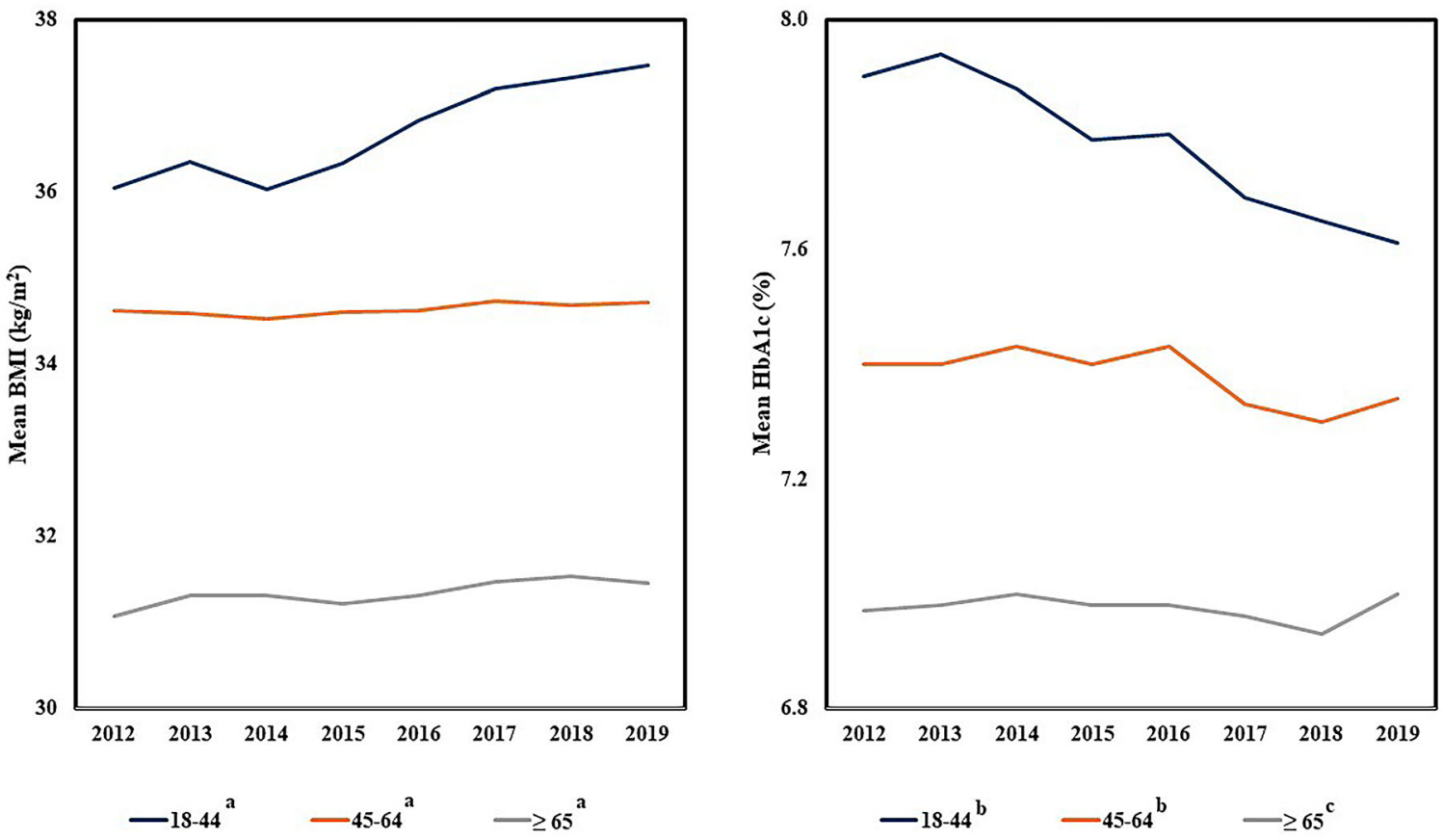

a - trend is positive and statistically significant $(P<0.05) ; b-$ trend is negative and statistically significant $(P<0.05) ; c-$ trend is not statistically significant $(P \geq 0.05)$ BMI - body mass index

Fig. 3 Trends in body mass index and HbAlc by age groups 
one $\mathrm{HbA1c}$ measurement was required per person in each year of interest. In addition, database limitations precluded inclusion of all patients for all years of the analyses, and not all individuals could be tracked for the duration of the study. However, a sensitivity analysis found that results were generally robust when examining only records from the first 6 years of interest (2012-2017), where there was significantly more consistency of patients over time. In addition, the analysis is primarily descriptive and as such did not examine how factors such as medication use or insurance status would affect trends in $\mathrm{HbA1c}$ or BMI. Finally, the analyses relied on diagnostic codes to identify individuals with $\mathrm{T} 2 \mathrm{D}$, a method which may not be as rigorous as results of laboratory tests or clinical assessments.

\section{CONCLUSIONS}

The findings of this study indicate that, for adults with T2D and for all age groups examined, BMI increased over the time period from 2012 to 2019 and that higher BMI was associated with higher HbA1c. While mean HbA1c remained unchanged over the study period for the entire cohort, the percentage of individuals achieving glycemic control decreased, despite the development of many new antidiabetic therapies over the study horizon. These results suggest that glycemic control may become more challenging as body mass increases and that therapies which decrease BMI as well as HbA1c may be important in the management of T2D.

\section{ACKNOWLEDGEMENTS}

Funding. Sponsorship for this study and the journal's Rapid Service Fee were funded by Eli Lilly and Company.

Authorship. All named authors meet the International Committee of Medical Journal Editors (ICMJE) criteria for authorship for this article, take responsibility for the integrity of the work as a whole, and have given their approval for this version to be published.

Author Contributions. Kristina S Boye had primary responsibility for study concept and data acquisition. Maureen J Lage had primary responsibility for conducting of analysis and drafting of manuscript. All authors (Kristina S Boye, Maureen J Lage, Shraddha Shinde, Vivian Thieu, and Jay Patrick Bae) contributed to the study design, interpretation of data, and critical revision of the manuscript.

Medical Writing. Writing assistance in the preparation of this article was provided by Ms. Patricia Platt. Ms. Platt conducted this work as a subcontractor of HealthMetrics Outcomes Research.

Disclosures. The authors Jay Patrick Bae, Kristina S Boye, Shraddha Shinde, and Vivian Thieu are employees and stockholders of Eli Lilly and Company. Maureen J Lage received compensation from Eli Lilly and Company for her work on this research.

Compliance with Ethics Guidelines. All data for this study were fully de-identified and Health Insurance Portability and Accountability Act (HIPAA) compliant and represented medical encounters that took place between January 1 , 2012, and December 31, 2019. Use of the data was obtained by Eli Lilly and Company via the purchase of a data license from International Business Machines (IBM) Corp. In addition, a data access rider from IBM allowed HealthMetrics Outcomes Research to access the data. Given the use of retrospective and de-identified data, ethics committee approval was not required.

Data Availability. The datasets used in this research are not publicly available due to licensing restrictions. Use of the data was obtained by Eli Lilly and Company via the purchase of a data license from International Business Machines (IBM) Corporation. In addition, a data access rider from IBM allowed HealthMetrics Outcomes Research to access the data. 
Open Access. This article is licensed under a Creative Commons Attribution-NonCommercial 4.0 International License, which permits any non-commercial use, sharing, adaptation, distribution and reproduction in any medium or format, as long as you give appropriate credit to the original author(s) and the source, provide a link to the Creative Commons licence, and indicate if changes were made. The images or other third party material in this article are included in the article's Creative Commons licence, unless indicated otherwise in a credit line to the material. If material is not included in the article's Creative Commons licence and your intended use is not permitted by statutory regulation or exceeds the permitted use, you will need to obtain permission directly from the copyright holder. To view a copy of this licence, visit http://creativecommons.org/licenses/by$\mathrm{nc} / 4.0 /$.

\section{REFERENCES}

1. Inoue Y, Qin B, Poti J, Sokol R, Gordon-Larson P. Epidemiology of obesity in adults: latest trends. Curr Obes Rep. 2018;7(4):276-88.

2. Centers for Disease Control and Prevention (CDC). Prevalence of overweight and obesity among adults with diagnosed diabetes-United States, 1988-1994 and 1999-2002. MMWR Morb Mortal Wkly Rep. 2004;53(45):1066-8.

3. Centers for Disease Control and Prevention (2020) Diabetes: national diabetes statistics report, 2020. Washington, DC. https://www.cdc.gov/diabetes/ library/features/diabetes-stat-report.html. Accessed 1 Feb 2021.

4. Mavian AA, Miller S, Henry RR. Managing type 2 diabetes: balancing HbA1c and body weight. Postgrad Med. 2010;122(3):106-17.

5. Gummesson A, Nyman E, Knutsson M, Karpefors M. Effect of weight reduction on glycated haemoglobin in weight loss trials in patients with type 2 diabetes. Diabetes Obes Metab. 2017;19(9): 1295-305.

6. American Diabetes Association. 8. Obesity management for the treatment of type 2 diabetes: standards of medical care in diabetes-2020. Diabetes Care. 2020;43(Suppl 1):S89-97.
7. Selvin E, Parrinello CM, Sacks DB, Coresh J. Trends in prevalence and control of diabetes in the US, 1988-1994 and 1999-2010. Ann Intern Med. 2014;160(8):517-25.

8. IBM Watson Health. IBM MarketScan research databases for life sciences and researchers [Internet]. Somers, NY 2018. https://www.ibm.com/ downloads/cas/0NKLE57Y. Accessed 6 Apr 2021.

9. IBM Watson Health. Data Sheet: IBM Explorys Electronic Health Record (EHR) Database [Internet]. Somers, NY; 2019. https://www.ibm.com/ downloads/cas/6VQK0DLL. Accessed 6 Apr 2021.

10. American Diabetes Association. 6. Glycemic targets: standards of medical care in diabetes-2020. Diabetes Care. 2020;43(Suppl 1):S66-76.

11. Centers for Disease Control and Prevention. Healthy weight, nutrition, and physical activity: about adult BMI [Internet]. Washington, DC; 2020. https://www.cdc.gov/healthyweight/assessing/bmi/ adult_bmi/index.html. Accessed 1 Feb 2021.

12. Zeger SL, Liang KY. Longitudinal data analysis for discrete and continuous outcomes. Biometrics. 1986;42(1):121-30.

13. Bae JP, Lage MJ, Mo D, Nelson DR, Hoogwerf BJ. Obesity and glycemic control in patients with diabetes mellitus: analysis of physician electronic health records in the US from 2009-2011. J Diabetes Complicat. 2016;30(2):212-20.

14. Weng W, Tian Y, Kimball ES, et al. Treatment patterns and clinical characteristics of patients with type 2 diabetes mellitus according to body mass index: findings from an electronic medical records database. BMJ Open Diabetes Res Care. 2017;5(1): e000382.

15. Leibson CL, Williamson DF, Melton LJ, et al. Temporal trends in BMI among adults with diabetes. Diabetes Care. 2001;24(9):1584-9.

16. Nakajima K, Suwa K. Excess body weight affects HbA1c progression irrespective of baseline HbA1c levels in Japanese individuals: a longitudinal retrospective study. Endocr Res. 2015;40(2):63-9.

17. Kennedy-Martin T, Robinson S, Boye K. Literature review on the association between BMI and glycemic control in patients with type 2 diabetes across eight countries [Internet]. Lawrenceville, NJ; 2020. https://www.ispor.org/heor-resources/ presentations-database/presentation/euro20203282/105211. Accessed 1 Feb 2021.

18. Dhatariya K. Diabetes: the place of new therapies. Ther Adv Endocrinol Metab. 2018;10: 2042018818807599. 
19. Frias JP, Dex T, Roberts M, Kaplan A. A review of the safety and adverse event profile of the fixed-ratio combination of insulin glargine and lixisenatide. Diabetes Ther. 2019;10(1):21-33.

20. Inzucchi SE, Bergenstal RM, Buse JB, et al. Management of hyperglycemia in type 2 diabetes, 2015: a patient-centered approach: update to a position statement of the American Diabetes Association and the European Association for the Study of Diabetes. Diabetes Care. 2015;38(1):140-9.

21. Schienkiewitz A, Schulze MB, Hoffmann K, et al. Body mass index history and risk of type 2 diabetes: results from the European Prospective Investigation into Cancer and Nutrition (EPIC)-Potsdam study. Am J Clin Nutr. 2006;84(2):427-33. 